\title{
Lengua, moda y sociedad
}

Las consideraciones que voy a desarrollar versarán, aunque sea de manera breve y somera, sobre dos asuntos radicalmente distintos: uno, de naturaleza especulativa: el análisis del concepto de signo y sistema lingüisticos; el otro, de carácter histórico-social: el análisis de la naturaleza de las prendas de la vestimenta en tanto que signos constituyentes de un sistema, presuntamente, identificable con los de las lenguas naturales. Sin embargo, ambos análisis los expondré, en la medida de lo posible, de modo simultáneo para facilitar la comparación de los resultados parciales obtenidos en cada uno de ellos y cuyas conclusiones serán el meollo de lo que pienso a este respecto: que la moda del vestir ni ninguna otra moda constituyen sistemas de signos identificables con los de las lenguas naturales.

Los distintos problemas teóricos serán tratados al hilo de la exposición del contenido de algunos de los epígrafes que la especialista en teoría de la moda Alison Lurie ofrece en el capítulo primero -donde está el núcleo de su interpretación lingüística de la misma- de su obra El lenguaje y la moda. Una interpretación de la formas de vestir, publicado en español en 1994, y en inglés en 1981 y 1992.

\section{LA MANERA DE VESTIR COMO SISTEMA DE SIGNOS}

Nada habría que objetar al enunciado de este epígrafe, si en el prefacio del libro se nos hubiera aclarado que la interpretación de la moda del vestido se enfoca desde el punto de vista semiológico, en su más amplio sentido; pero no es así. Ya en la primera línea del mismo nos encontramos, de hoz y coz, con una conclusión, que no es resultado de ningún análisis previo: la paralela identificación de moda y lengua natural: "Como casi todas las lenguas habladas y escritas, el lenguaje de la moda está siempre en continuo cambio" (p. 21). Y ¿por qué casi y no como todas las lenguas habladas y escritas? ¿Y por qué no como todas las habladas? Las lenguas que no conocen el freno de las escritura son, precisamente, las que se ven sometidas a un mayor y más enérgico pro- 
ceso de cambio, de desgaste, por causas tan evidentes y elementales que no procede exponer.

También están en continuo cambio los regímenes alimenticios de muy distintos pueblos y épocas; también cambia con frecuencia la reglamentación del tránsito rodado en las ciudades y, en función de la misma, lo que ayer estaba prohibido hacer hoy no lo está; y lo que ayer era un requisito para circular libremente, hoy ya no lo es, y ha aparecido otro antes ignorado; también cambia con relativa rapidez la normativa laboral respecto de obligaciones, derechos, horarios, etc. de los trabajadores; también cambian los hábitos familiares y sociales de convivencia y de comportamiento ciudadano, y a nadie se le ha ocurrido, en ninguno de los casos mencionados - y en otros muchos de naturaleza social de que hago gracia - hablar de que constituyen sistemas de signos identificables con el de las lenguas, como no podía ser de otra manera. Y es, a mi juicio, por una causa indiscutible, a fuerza de ser evidente: que el hecho de la existencia de cambio, por sí mismo y por sí solo, no constituye el fundamento de la naturaleza del signo lingüístico. El cambio es algo común y consustancial con la existencia de las entidades vivas naturales, intelectuales, morales, sociales, etc., sean o no signos, formen parte o no de un sistema, y no específico de ninguno. La esencia del signo lingüístico reside en algo radical y, simultáneamente, específico.

Desde Saussure hasta hoy, la naturaleza del concepto de signo ha sido concebida de muy distintas formas, como puede comprobarse consultando cualquier diccionario terminológico de lingüística moderna. Además, no sólo se habla del concepto de signo lingüístico, en general, sino también, en particular, de signos lingüísticos categoremáticos, sincategoremáticos, diacríticos, expresivos, icónicos, metalingüisticos, etc. ¿Quién no ha oído hablar de que las señales luminosas que emiten los semáforos forman un conjunto de signos convencionales, ya que arbitrariamente se le ha asignado al rojo la información de prohibición o peligro, al verde la de paso libre, al parpadeante amarillo la de precaución? Se habla, incluso, de signos simbólicos, con lo que ya queda diluida la radical diferencia existente entre signo y simbolo, científicamente establecida.

Dando por supuesto y por conocido lo que acabo de referir, y para evitar malentendidos, voy a centrarme en la archiconocida idea saussuriana de signo lingüístico —origen de todas las demás, pues no son más que especificaciones, generalizaciones, fusiones y confusiones de ella.

Según el lingüista ginebrino, son dos las propiedades - taxativamente, dijo principios- que conforman la especial naturaleza del signo que constituye sistemas lingüisticos: la arbitrariedad y la linealidad. Propiedades, hay que añadir, en esta ocasión, al menos, que no son compartidas, de 
modo simultáné, con ninguna otra clase de signo y, sobre todo, con la prenda de vestir. He dicho, intencionadamente, de modo simultáneo, porque la arbitrariedad o convencionalidad es compartida con otros, pero no así la linealidad, y viceversa. Otros signos, los llamados naturales, por el contrario, como, por ejemplo, los cambiantes colores que una fruta presenta en el árbol, nos transmiten una información que en absoluto tiene nada de arbitraria y, mucho menos, de lineal. Es cierto que no siempre el color verde de la manzana quiere decir que no esté madura, ni el rojo que esté en sazón, porque hay especies que siempre están verdes, con mayor o menor intensidad, según el grado de madurez, o siempre rojizas, en idénticas circunstancias; pero es lo normal y lo obligado decir, en español, que esta fruta está verde, para indicarnos que no está madura. En cualquier caso, la experiencia material intelectualizada - hecho que ocurre siempre después de haber visto, tocado y observado una "cosa" natural o artificial- nos hace saber que el verdor de la fruta va casi sistemáticamente asociado a la falta de maduración y que, por el contrario, la sazón, según las frutas, presenta diverso colorido: el níspero maduro es dorado, la cereza o la fresa son rojas o rojizas, las manzanas llamadas golden o verde doncella, una vez maduras, se distinguen perfectamente por la intensidad y suavidad, respectivamente, del amarillo de su piel. Pero, además, esta información no se recibe de manera sucesiva, lineal, como les ocurre a los fenómenos acústicos, sino instantánea, espacial, dado que el oído y el ojo la registran sensorialmente, por su especial constitución anatómica, de modo tan diverso.

En los tratados de lógica, se dice que el humo es signo del fuego, por aquello de que hay relación natural de dependencia entre el uno y el otro. En efecto, el DRAE s.v. signo, haciéndose eco de esta circunstancia dice que signo natural es 'el que nos hace venir en conocimiento de una cosa por la analogía o dependencia natural que tiene con ella: $E l$ bumo es SIGNO del fuego'. Ahora bien ¿cómo se puede hablar de "lenguas naturales", si el signo lingüístico no implica la relación de naturaleza, de dependencia natural entre sí mismo y la "cosa", mental o material, significada? No obstante, la expresión cobra sentido si la confrontamos con la de alenguas artificiales", como la de los gestos, la de los silbidos o el morse, porque no son las que se identifican hipostáticamente con la persona. Pero están formadas por signos arbitrarios y lineales, como resultado de una convención humana. Pues bien, mucho antes que en los tratados de lógica, en uno de medicina galénica, originalmente redactado en latín, en 1384, por el converso Juan de Aviñón, titulado Sevillana medicina y, posiblemente, traducido a finales de ese mismo siglo, se expone el pensamiento de Aristóteles en el que bumo equivale a prueba natural de la existencia 
del fuego. Para evitar confusiones, leeré el párrafo que ahora interesa, en español moderno, pero manteniendo el ritmo y lo reiterativo del original romance, según la versión y edición que del mencionado tratado preparo. Dice el galeno afincado en Sevilla, respecto de la naturaleza de la prueba:

una es demostrativa; la otra no; la demostrativa es la que prueba lo último por lo primero; la no demostrativa procede al contrario: prueba lo primero por lo que sigue; así, por ejemplo, al que le pregunte a otro ¿hay humo en aquella casa? le responderá: sí, hay humo; y en virtud de que el humo presupone el fuego, es necesario que haya humo; por consiguiente, en esta casa hay humo; a esto se llama razonamiento demostrativo, por cuanto prueba lo último, que es el humo, por lo primero, que es el fuego; pero si preguntara lo contrario diciendo, si hay fuego en aquella casa, le responderá: sí, porque donde hay humo, hay fuego; y puesto que allí hay humo, parece que hay fuego; esta prueba se llama no demostrativa, porque con lo último se prueba lo primero; la mayoría de las pruebas de las cosas naturales son de esta segunda clase (f. ${ }^{\circ} 23 r-23 v .^{\circ}$ ).

Todo este párrafo aristotélico, en versión intelectual medieval rudimentaria, es la expresión de lo que he llamado experiencia intelectualizada, abstraída por medio de la observación de la realidad, que es el fundamento del principio lógico de la causalidad natural.

La presentación de estos ejemplos de "signos naturales", mejor sería decir "señales naturales" —el color de la fruta y el bumo del fuego- intentan hacer comprender de manera sencilla que tanto los colores de la fruta, cosas naturales, como las prendas de moda, cosas artificiales, son signos en sentido semiológico amplio, pero no en el específico que lo es el lingüístico natural. Por lo tanto, creo que queda suficientemente clara la enorme diferencia que hay entre preferencias - porque en ellas consiste la esencia de la moda- sobre usos y hábitos sociales, considerados como signos o sistemas de signos, y el lingüístico y el natural, por las siguientes razones; diferencia respecto del signo lingüístico: $1 .^{\mathrm{a}}$ ) el significado de la unidad prenda no es arbitrario en sí mismo, sino que lo es en función de interpretaciones sociológicas de lugar y tiempo; y 2.a) su percepción no es lineal, sino espacial, instantánea; diferencia respecto del natural: $\left.1 .^{a}\right)$ la hechura, color y dimensión, su apariencia, en general, no obedece al principio de causalidad; y $2 .^{a}$ ) porque la percepción de la prenda depende de la perspectiva que se adopte, según se observe desde un punto o de otro.

Otro paso más es esta ceremonia o festival de la confusión científica que da la autora del libro mencionado, para cimentar su punto de vista, lo encontramos cuando nos trae a colación unas palabras de Balzac, sacadas de la novela Hija de Eva (1839), para demostrar la antigüedad de 
la concepción de la manera de vestir como lenguaje. Dijo el creador de la más grande y, frecuentemente, ramplona y cutre, epopeya social urbana - por el tipo de sociedad que retrata-, que, para una mujer, su vestimenta es «una manifestación continua de los pensamientos más íntimos, un lenguaje, un símbolo" (p. 21). No hay que ser un lince para darse cuenta de que Balzac hace una hermosa metáfora de la más que posible interpretación identificadora entre mujer y vestido, dando por supuesto - creo- que se trate de una mujer cultivada y consciente de lo que es y de lo que quiere ser; diríamos que, en este caso, la vestimenta refleja su personalidad; pero esta metáfora debe de entenderse -creo- en cuanto que un determinado vestido está pensado por su calidad, forma y valor social por quien o para quien ha de llevarlo. Interpretación sólo aceptable para una sociedad o en un estrato social poco o nada amante de la reglamentación y del dirigismo ordenancista. Porque ¿cómo es posible aplicar este juicio de valor moral y social a las etnias o capas desheredadas de la sociedad medieval o, incluso, moderna, cuando se ven obligadas a no poder utilizar en su atuendo determinadas prendas o, lo que es peor, a llevar distintivos sobre su ropa que las identifique como pertenecientes a grupos sociales marginados, con sólo obligaciones y casi ningún derecho? En las Cortes de Madrigal de 1476, tenidas por los RR. CC., se dice:

\begin{abstract}
Otrosy, sennores, bien sabe vuestra alteza como, segun las leyes de vuestros rreynos los judios e los moros han de traer en las rropas de ençima sennales acostunbradas por donde sean conosçidos entre los christianos; e esto no enbargante, veemos que los judios e moros que viuen en vuestros rreynos e los mas dellos no traen las dichas sennales, ante andan los vnos e los otros vestidos de rropas de pannos finos e de rropas de tal fechura, que no se puede conosçer si los judios son judios o si son clerigos, o letrados de grande estado o autoridad [...]. Que los judios e las judias trayan sus sennales coloradas en el honbro derecho [...] e los moros traya cada vno su capellar verde sobre toda la rropa [...], e las judias luneta azul en el honbro derecho en la rropa de encima (Cortes IV, 101).
\end{abstract}

Se le daba el nombre de capellar a un tipo de capa morisca con "capilla" o capuchón, de lana o de seda, y de forma semicircular ${ }^{1}$. Y el de luneta, según el DRAE s.v. 2. 'Media luna que como adorno usaban las mujeres en la cabeza y los niños en los zapatos'. Es una pena que el erudito redactor de esta entrada del diccionario haya olvidado o no conozca el infamante sentido con que también se utilizaba llevándola en el hombro.

1 Carmen Bernis, Trajes y modas en la España de los Reyes Católicos. II. Los bombres (Madrid: CSIC, 1978), p. 68 s.v. 
En pleno siglo XVI, año de 1552 , se dice lo que sigue, respecto de lo que estamos tratando:

Otrosi: mandamos que los oficiales menestrales de manos, sastres, zapateros e carpinteros, herreros, herradores, tejedores, pellejeros, tundidores, curtidores, esparteros e especieros, e de otros cualquier oficios a estos semejantes, o mas bajos, e obreros e labradores, ni jornaleros, no puedan llevar, traer ni trayan seda alguna, excepto gorras, caperuzas o botones de seda; e sus mugeres solamente puedan traer sayuelos o gonetes de seda, e un ribete en los mantos que trageren de paño, so la dicha pena ${ }^{2}$.

Sayuelos y gonetes están, respectivamente, relacionados con saya y gonela. Los términos sayuelos y gonetes eran utilizados, respectivamente, en Castilla y Aragón. Lo más probable -al menos eso parece deducirse del contexto- es que designaran el mismo tipo de vestido. En efecto, sayuelo era uno de los nombres que se daba a las prendas muy cortas que llevaban los hombres sobre el jubón; pero también lo era "de un cuerpo femenino, posiblemente el mismo que por otro nombre se llamaba gonete, ${ }^{3}$, prenda exterior, corta con mangas ${ }^{4}$. Gonela y gonete son derivados del it. gonella, que, a su vez, es diminutivo de gonna 'falda' (<lat. tar. GUNNA, del gal. gunna 'piel') ${ }^{5}$.

Después de este pequeño excurso histórico y lexicológico, podemos estar seguros de que la vestimenta y los adornos que suelen llevarse no siempre reflejan la íntima personalidad del que los lleva. Las cosas y los términos tienen, la mayoría de las veces, valor históricosocial o significado sociolingüístico, respectivamente, en función de los tiempos y de las circunstancias.

Por otra parte, en el texto de Balzac, hay planteados dos problemas: el primero, ya considerado: el vestido es "manifestación continua de los pensamientos más íntimos" de una mujer; el segundo es de naturaleza terminológica y conceptual, si se lee con ánimo científico; en caso contrario, no pasa de ser una hermosa metáfora, respecto de la posible identificación entre la forma de vestir de una mujer y el reflejo de su mundo interior; dice, también, Balzac que el vestido es un lenguaje, un símbolon. De dos formas puede interpretarse este final: $\left.1 .^{a}\right)$ que la manera de

2 Serafín María DE SOTTO, Discurso bistórico sobre el trage de los españoles desde los tiempos remotos hasta el reinado de los Reyes Católicos (Madrid, 1869), p. 195.

3 Carmen BERNIS, Trajes, p. 123, s.v.

$4 \quad$ Ibid., p. 91.

5 Manlio CoRtelazzo e Paolo Zolli, Dizionario etimologico della lingua italiana (Bologna, 1980), II, s.v. gonna. 
vestir de una mujer puede ser, alternativamente, lenguaje o simbolo; sería cuestión de pareceres discutibles; y $2{ }^{2}$ ) que la manera de vestir de una mujer es perfectamente caracterizable con dos sinónimos: lenguaje y simbolo, lo que significaría desconocer la particular naturaleza de una y otra palabra.

Es sabido que el vehículo de manifestación del signo lingüístico o, lo que es lo mismo, del lenguaje articulado -en el doble sentido martinetiano de articulación - es de naturaleza lineal y acústica: el sonido, porque la escritura no es más que una segunda convención tan arbitraria y tan lineal como el hecho de unir un determinado significante con un determinado significado; pero hay una diferencia: la arbitrariedad oral se remonta al origen de las lenguas y, por lo tanto, es natural e inexplicable; la arbitrariedad que une grafema y sonido es producto de una convención cultural. Por el contrario, el vehículo de manifestación del símbolo ni es arbitrario ni es acústico, sino motivado y visual. El símbolo es la representación visual y sintética de una idea; carece, lo mismo que la vestimenta, de capacidad de articulación en secuencias significativas por medio de recursos sincategoremáticos, es decir, de elementos de relación. Los emblemas que adornan los uniformes militares, al igual que la balanza y la espada sostenida por el mórbido brazo de una matrona, o la calavera sobre dos tibias cruzadas, por ejemplo, son símbolos, son síntesis espaciales - no lineales- imaginadas de significado unívoco, que no se prestan, en consecuencia, a interpretación sociológica libre ni sinonímica. Los símbolos representan ideas congeladas; los signos significan multitud de conceptos, según el decurso y el momento. Los símbolos son objeto de identificación social con la idea que encarnan: se dice que las banderas de las naciones representan a la patria, es decir, el conjunto de valores morales, sociales y políticos de los pueblos y, como a tales representaciones, se les rinden los llamados honores de ordenanza. Los signos lingüísticos o son portadores de abstracciones de primer grado, como ocurre en el caso de las palabras, transmisoras de realidades exclusivamente mentales: libertad, entusiasmo, vileza, ancho, alto, etc., o lo son de abstracciones de segundo grado, como ocurre con los términos, que apuntan a cosas, naturales o artificiales, cuya existencia real es exterior a la mente, por lo que el conocimiento sensorial de la "cosa" es exigencia previa a la creación del concepto. Item más, mientras que los signos son unidades de referencia de referidos mentales o materiales; mientras que los símbolos son unidades sintéticas con referencia a referidos sólo mentales, las prendas de vestir son referidos materiales o, lo que es lo mismo, realidades materiales designadas por signos lingüísticos. Por lo tanto, ¿cómo concebir el conjunto de vestidos, que en un momento histórico 
pueden estar de moda, simultáneamente, como lengua y como realidad material social por ella designada? Es muy probable que los semiólogos tengan contestación semiológica, pero no lingüística, toda vez que Roland Barthes dijo, en "Las enfermedades del vestido", según Alison Lurie, que la vestimenta del teatro era un "tipo de escritura", cuya base es el signo, aunque parece ser que Barthes no precisó que este signo fuera de condición lingüisticonatural.

Todas las divagaciones de los semiólogos, en su legítima ambición de prestar rigor científico a todo lo que pueda considerarse sistema social de signos, por vía de la comparación con el sistema de signos por antonomasia que es la lengua, no pueden pasar de ser brillantes interpretaciones de hechos y circunstancias, como los castillos de artificio que abren las puertas a los días de jolgorio.

\section{GRAMÁtica Y VOCABULARIO DE LA MODA}

Otro paso, propio de diletante, tan atrevido como irresponsable, en un mundo tan complejo como el de la lingüística teórica, es el de defender - literalmente- esto: "nuestras ropas conforman un vocabulario y una gramática tan precisos y tan llenos de intención subconsciente como cualquier otro lenguaje..

Demostrado - supongo- que el conjunto de la vestimenta, en un período dado de la vida de un pueblo, no puede constituir una lengua, porque las unidades - las prendas — no son signos lingüísticos, sino cosas que pueden ser interpretadas desde un amplio punto de vista semiológico, está implícitamente demostrado que ni la moda tiene "gramática" ni posee en sí misma vocabulario, porque conditio sine qua non, para que una lengua exista, es que posea unas reglas combinatorias para construir secuencias articuladas con unidades lingüísticas de distinto rango, es decir, una gramática.

Hace ya muchos años, escribí que

una gramática es la descripción del funcionamiento de un número determinado de elementos, en un momento dado, de acuerdo con unas normas combinatorias. Los elementos y las relaciones que los ligan forman un sistema. La gramática de una lengua, en cualquier caso, es el resultado de la integración de subsistemas, generalmente, correlativos ${ }^{6}$.

¿Cómo descubrir en el conjunto de los vestidos del hombre o de la mujer las reglas o normas combinatorias de naturaleza sociolingüística de

\footnotetext{
6 José MONDÉJAR, "Lingüística e historia", RSEL, 10, 1 (1980), p. 24.
} 
las unidades, cuyo único principio de cambio esté regulado por el uso, y no por el capricho estético de un modista de estación en estación? Plantear siquiera este problema me parece, por inconsistente, que va más allá de lo racionalmente permitido, incluso, en una divagación semiológica.

Pero todavía no han terminado las sorpresas que nos depara la teoría lingüística de la moda. Ya sabemos que las unidades mínimas de la moda son las prendas; pues bien, ahora hay que añadir que también son los peinados, las joyas, los adornos, etc., lo que no es poco; pero lo que verdaderamente sorprende es descubrir que "al menos en teoría, este vocabulario es tan amplio o más que el de cualquier lengua hablada, pues incluye cualquier prenda, cualquier peinado y cualquier tipo de adorno que se haya podido inventar jamás" (p. 22). ¿Cómo es posible identificar, seriamente, prenda y término que la denomina? ¿Sería posible hacer un "prendario" sin emplear los diversos elementos léxicos o vocabulario que designan las prendas?

Una de las características del conjunto del vocabulario de las lenguas naturales es la de la existencia, dentro del mismo, de la sinonimia - varios elementos que designan lo mismo- y de la polisemia - un elemento que designa varias realidades mentales o materiales- capacidad que no comparte con las lenguas artificiales. ¿Gozan las prendas, como presuntas unidades de un sistema, de esas propiedades? ¿Gozan las prendas, al igual que los signos lingüísticos, de la capacidad de composición y derivación? ¿Qué clase de vocabulario es ese que está formado por unidades de constitución pétrea, habida cuenta de su incapacidad de creación léxica y de movilidad semántica? Además, a mi juicio, la unidad prenda sólo es interpretable en función de sus dos características constitutivas: la utilitaria y la estética, pero que no son de su exclusiva pertenencia, porque las comparte con otros sistemas de signos, pero no con el lingüístico. El signo lingüístico es útil, pero en sentido y con finalidad muy distintos; con él se puede crear belleza, pero, en sí mismo, ni es bello ni deja de serlo.

A pesar de lo dicho, todavía queda el asunto más importante: el de la relación lengua-pensamiento y lengua-realidad. La moda, frente a la lengua, sólo representa unas determinadas corrientes estéticas, en períodos concretos de tiempo, de una determinada sociedad, en la que la prenda puede desempeñar un papel discriminatorio, respecto de clases y etnias, como hemos visto. La lengua, como dijo el romántico W. von Humboldt, forma una unidad con el pensamiento; cada lengua, por medio de su vocabulario, es la expresión de una concreta concepción del mundo. He aquí unas palabras suyas a este respecto, rebosantes del más entusiasta idealismo: 
La lengua es el órgano estructurador del pensamiento. La actividad intelectual, absolutamente espiritual, absolutamente mental y, en cierta medida, tan efímera que no deja huella, se exterioriza y hace perceptible el sentido por medio de los sonidos en las palabras [...]. En la lengua, es tan maravillosa la individualización dentro de la comunidad, que sería igualmente correcto decir que todo el género humano posee una sola lengua, como que cada persona tiene una especial ${ }^{7}$.

Para la filosofía marxista, la lengua es reflejo de la realidad, es decir, por medio de ella conocemos el tipo de organización social, material y política, de los pueblos, además de los medios y modos de producción. Oigamos al marxista Adam Schaff:

En oposición al convencionalismo, que concibe el lenguaje como una formación arbitraria, decimos que el lenguaje refleja la realidad. La teoría del reflejo se basa en la teoría marxista del conocimiento. [...] La concepción del lenguaje como reproducción de la realidad no es en absoluto privativa de la teoría marxista del conocimiento como reflejo. Lo que no deja de constituir una razón más a favor de la conveniencia de considerar con mayor detenimiento la tesis de que el lenguaje "refleja" la realidad. [...] Sólo entonces tenemos el camino abierto para descubrir el carácter de los diversos "lenguajes" y captar así lo específico del lenguaje de los signos lingüísticos en contraposición a otros "lenguajes" ${ }^{8}$.

Creo que, con estas dos autorizadas citas, queda rematada la tesis defendida en estas páginas de la especificidad del signo lingüístico y, en consecuencia, de las lenguas naturales, frente a otros posibles "lenguajes".

\section{MODA Y SOCIEDAD}

No hace mucho, he reproducido unas palabras de Balzac, de significado metafórico, en las que se afirma que el vestido es un "lenguaje, un símbolo". Visto ya que la indumentaria no es una lengua, sensu stricto, habrá que indagar si la naturaleza del concepto símbolo es aplicable al vestido, en tanto que manifestación material concreta, según el tipo y el modelo de sociedad que lo utiliza; o si, al menos, determinadas prendas pueden tener valor simbólico.

7 Wilhelm vON HUMBOLDT, Über die Verschiedenbeit des menschlichen Sprachbaues und ibren Einfluss auf die geistige Entwickelung des Menschengeschlechts [Berlín, 1836] (Bonn, 1968), p. 433.

8 Adam SCHAFF, "Sobre la necesidad de una investigación lingüística marxista", Ensayos sobre filosofia del lenguaje (Barcelona, 1973), pp. 24, 25 у 27. 
Es comúnmente sabido, por evidente, que una manera de simbolizar el poder social y político, en cualquiera de sus grados, se manifiesta en la riqueza, la forma y adornos del vestido. Un ejemplo paradigmático, aunque en los tiempos que corren pueda verse como arcaismo de una ceremonia teatral, pero no se olvide que cargada de contenido político y democrático, es la vestidura que luce la Reina de Gran Bretaña cuando en la Cámara de los Comunes, no en la de los Lores, pronuncia el discurso de la corona, al inaugurarse una nueva legislatura. Ese lujo excesivo no sólo cautiva al pueblo, sino que empequeñece a los circunstantes, porque es, pienso yo, la manifestación simultánea de la potestas y de la auctoritas. Por esa razón, la nobleza, y después la burguesía y el clero, siempre ha velado por que el pueblo llano -el labrador, el menestral, el comerciante, entre otros muchos - no pueda utilizar ropa de calidad, color y forma que induzca a confusión de clase o estamento social. Pero, al mismo tiempo, el vestido discrimina y sirve para identificar el grupo étnico e, incluso, en la Edad Media, el gremio al que se pertenecía. A veces, ya se ha visto, se ha obligado a llevar ciertos distintivos, no suntuarios, claro, que pregonen la pertenencia a una determinada religión o grupo marginado, dentro del común de la sociedad, como veremos, de nuevo, más adelante.

Es verdad que ahora, en general, y a partir de 1789 , fecha de la revolución francesa, la de mayor trascendencia dignificadora política y humana ocurrida en el mundo, cada uno viste según su antojo, cuyo límite viene marcado por la capacidad de inversión dineraria. No obstante, se pretenden dos fines muy diferentes cuando el anónimo ciudadano se viste sus mejores galas para ser recibido, y cuando lo hace el conocido poderoso - sea cual sea la naturaleza de su poder: en el primer caso, se pretende agradar, a la vez que se rinde homenaje de respeto; en el segundo, se hace ostentación de superioridad.

Hasta llegado el siglo XIX, en que se dejaron de publicar en Europa las llamadas "leyes suntuarias", la manera de vestir y de aparecer en público estaba - teóricamente- regulada por el poder público. En España, en las reuniones de Cortes, se tomaban los acuerdos necesarios para que, por una parte, el afán de lujo no se desmandara; y, por otra, para que determinados tejidos y prendas no fueran llevadas por las gentes de "vil condición", como dijo el Marqués de Santillana, al referirse a la gente que se divertía con los romances.

La última Pragmática de naturaleza suntuaria publicada en España, a juzgar por lo que se lee en la historia del lujo de Sempere y Guarinos, data de 1783: 
por la que se prohibe, que ninguna persona de qualquiera clase que sea pueda usar, ni traher en los coches, berlinas, y demás carruages de rua, mas de dos mulas, o cavallos dentro de los pueblos... ?

Es a partir del siglo xIII, sobre todo a su mediación, cuando, a causa del florecimiento comercial de las ciudades, el afán de lujo se dispara, pero no sólo en las clases pudientes o dominantes: nobleza, clero y burguesía, sino también en las de reciente poder adquisitivo como fruto de su trabajo: artesanos, comerciantes, profesionales, y toda clase de "hombres buenos". Tejidos y una considerable variedad de mercancías llegan a Castilla por los puertos del Norte y de Sevilla. En el espléndido vocabulario, Los nombres de los tejidos en castellano medieval de Martínez Meléndez ${ }^{10}$, se recogen estas líneas de la Crónica General, referidas a la actividad comercial del puerto de Sevilla:

apuertan alli con todas mercadorias de todas partes del mundo: de Taniar, de Çepta, de Tunez, de Bogia, d'Alexandria, de Jenua, de Portogal, de Pisa [...], et de otras muchas partes dallen mar, de tierra de cristianos et de moros (II, 769a).

Es en este siglo, como consecuencia natural de la riqueza comercial y productiva, cuando empiezan a aparecer las leyes prohibitivas del lujo, para poner freno a la ostentación y al despilfarro en la manera de vestir -que, sobre todo, sigue modas ultramontanas-, en la compra de ricas telas, adornadas con franjas o galones de oro y plata, en la extensa variedad de pieles y de joyas, en las cabalgaduras brillantemente enjaezadas, en el número sirvientes, etc. Y fue en el Ordenamiento de las Cortes de Valladolid, de 1258, otorgado por Alfonso X, cuando se promulgaron las primeras leyes suntuarias en Castilla, por razones de Estado: según el Rey, habló con sus consejeros sobre

muchas cosas sobeianas que se fazien que eran a danno de nos e de toda mi tierra e acordaron delo toller e de poner cosas sennaladas e çiertas porque biuades (Cortes I, 55),

es decir, se trató de los gastos superfluos que se hacían y que repercutían en perjuicio de las arcas del mismo Rey y de las de su reino; por ello ordena que se cumpla, excluido el monarca, porque taxativamente se dice "Que uista el Rey como touier por bien e quantos pares de pannos el quisiere", lo que él mismo dispone:

9 Juan SEMPERe y GuARINos, Historia del luxo, y de las leyes suntuarias de España (Madrid, 1788), II, p. 172.

10 Granada: Universidad de Granada, 1989. 
Et manda el Rey que los sus escriuanos nin ballesteros nin sus falconeros nin ningunos de los ommes de su casa nin de la reyna que non trayan pennas blancas nin çendales nin siella de barda dorada nin argentada nin espuelas doradas nin calças de escarlata nin çapatos dorados nin sombrero con oropel nin con argent pel nin con seda, sinon los seruiçiales maiores de cada un officio (Cortes I, 55).

En el mismo Ordenamiento se insiste dos veces más en parecidas prohibiciones.

Que el lujo personal y la fastuosidad llegaron a alcanzar, en el siglo XV, los límites del despilfarro más insultante, lo muestra la Crónica del Condestable Lucas de Iranzo, con motivo de la procesión civil organizada desde la residencia del Condestable y de su futura esposa hasta la iglesia mayor de Jaén; he aquí unas líneas que describen el atuendo personal y el enjaezado de los caballos:

los dichos señores fueron en la manera siguiente: el señor condestable leuaua un - vestido vn jubon de muy fina chaperia de oro todo cubierto [...] y sobre aquel una ropa d'estado en demasia roçagante de vn carmesi velludo morado, forrada de muy preçiadas y valiosas cebellinas; en la cabeça vn capello negro de muy nueua gujsa con vn muy rico joyel en el rollo bordado de muy ricas jemas, con vna guarnjçion de oro de mucho valor en somo los onbros [...]; ençima de vn hobero trotón [...] su cola con vna guarnjçion asas rica y bien pareçiente, delantera y grupera de muy fino oro sobre vn terçiopelo negro de nueua y muy discreta ynvençion; vn baston en la mano.

Salio la señora condesa con vn muy riquisimo brial, todo cubierto de la mjsma chaperia del jubon del señor, y ençima vna ropa de aquel carmesi morado, con vn rico collar sobre los onbros [...], ençima de vna facanea muy linda blanca, la silla y delantera y grupera de la qual muy ricamente guarnjda ${ }^{11}$.

A partir del XIII, cualquier tipo de prohibición, a éste y otros respectos suntuarios, tendrá el mismo fundamento: el gasto excesivo en telas, pieles y adornos va en detrimento de la riqueza del país, por encima de cualquier consideración ética. En las Cortes de Segovia de 1532, se le suplica al Emperador Carlos que

mande guardar la prematica de los brocados y telas de oro y plata, bordados, dorados y plateados, por tiempo de diez años, porque se excusen muchos gastos que en estos reynos se hacen muy sin provecho (Cortes IV, CI, 571).

Para terminar, quiero mostrar cómo este tipo de sociedades - la estamental del medievo y la clasista posterior- procura, además de de-

11 Francisco DíAz MonTESinos, Léxico de los Hechos del condestable Miguel Lucas de Iranzo (Madrid: Universidad Complutense de Madrid, 1985), I, pp. 123-124. 
fender la estratigrafía social, que los grupos marginados, por razones religiosas o de "oficio", queden bien identificados, para evitar confusiones o malentendidos sociales. Las señales de identificación medieval de los grupos religiosos ya las conocemos; ahora, una sola referencia a lo que debía distinguir en la sociedad imperial de Carlos I, por privación, a las amujeres enamoradas" - elegantísima perífrasis que alude a las que hoy, toscamente, se llaman "trabajadoras del amor" - de las restantes, pues se pretende obligarlas a que vayan vestidas de manera zarrapastrosa, aunque no se diga explícitamente, pero sí prohibiéndoles llevar arreos lujosos, porque son "malas" y conviene que se distingan de las "buenas":

Suplicamos a Vuestra Magestad asymismo que las mugeres enamoradas, que conoçidamente son malas de sus personas no puedan traer, ni trayan en sus casas ni fuera dellas oro de martillo, ni perlas, ni seda, ni faldas, ni verdugados, ni sonbreros, ni guantes, ni lleven escuderos, ni pajes, ni rropa que llegue al suelo porque son eçesivos los gastos y oros y sedas que traen, que asy no son conoçidas entre las buenas, Vuestra Magestad con grandes penas lo mande asy cumplir y executar (Cortes IV, 673, 109).

De este texto, sólo procede hacer una curiosa aclaración: la del término verdugado. El verdugo es el nombre del retoño o rama tierna de un arbusto, con la que se hacían los aros que, cosidos, servían para armar el brial - traje de lujo femenino largo y ajustado al talle- y darle forma acampanada. Al parecer, este invento de la moda castellana femenina del Xv, fue obra de Juana de Portugal, mujer de Enrique IV, "para ocultar la evidencia de las infidelidades a su marido", según el cronista y lexicógrafo Alfonso de Palencia ${ }^{12}$. Ya en el siglo Xvi, verdugo o verdugado es una especie de faldilla interior, rígida o armada de aros, que servía para ahuecar la basquiña, nombre de una falda de color negro originaria del país vasco (ver DRAE s.v.).

Final. Los razonamientos de naturaleza semiológica sobre los presuntos sistemas de signos sociales, basados en la analogía con los sistemas de signos lingüísticos, unas veces, son brillantes, otras, penosos, y nunca, científicos.

JOSÉ MONDÉJAR

Universidad de Granada

12 Enriqueta Albizua Huarte, El traje en España, apéndice a la obra de James LAVER, Breve bistoria del traje y la moda (Madrid, 1995), p. 313. 
Se trata de demostrar, tras la exposición de los conceptos básicos de signo, unidad, articulación y sistema lingüísticos, que el conjunto de prendas —unidades- utilizadas en un determinado período histórico no constituyen un sistema, y, mucho menos, idéntico al de las lenguas naturales - a pesar de que lengua y moda estén sujetas al proceso de cambio- dada la incapacidad de cada una de esas unidades de articularse dentro del conjunto en función de recursos de la misma naturaleza, para constituir niveles de organización equivalentes a los de unidades mínimas - fonemas-, unidades formales - formas articuladas en paradigmas - y unidades funcionales — sintagmas. Sólo de manera analógica y en el más amplio sentido semiológico puede hablarse de "lengua» de la moda.

This paper aims to show that the set of garments used in a particular historical period does not make up a system identical to the one occurring in natural languages. This will be done after considering the basic concepts linguistic sign, linguistic unit, linguistic articulation and linguistic systems. Despite the fact that both language and fashion are related to a process of change, garments are unable to become articulated within a set in relation to resources of the same nature. Besides, garments cannot make up organizational levels equivalent to the levels of minimal units - phonemes-, formal units - forms articulated paradigmatically - and functional units - phrases. Only in an analogical manner and in a broad semiological sense can one speak of the "language" of fashion. 